\section{Tree-ring carbon-isotope ratios re-examined}

SIR--The tree-ring ${ }^{13} \mathrm{C} /{ }^{12} \mathrm{C}$ ratio has been used as an indicator of historic climate and/or atmospheric composition despite the difficulties in interpreting the results due to other competing effects. Stuiver and Braziunas have reported a $\delta^{\prime} \mathrm{C}$ gradient in 1850 tree-ring cellulose (from conifers). Their results show that $\delta^{13} \mathrm{C}$. the carbon-isotope ratio relative to a standard, increases from $-19 \%$ near $35^{\circ} \mathrm{N}$ to $-24 \%$ at $65^{\circ} \mathrm{N}$. (The $\delta^{\prime 3} \mathrm{C}$ value is more positive when the sample is enriched in ${ }^{13} \mathrm{C}$.)

Stuiver and Braziunas also reported similar dependencies with latitude (N or S) in cellulose and wood from deciduous and coniferous modern tree rings (although the deciduous trees are about $3 \%$ more negative than the conifers). With respect to the latitudinal dependence, the authors suggest "relative humidity and temperature appear to be the controlling factors, with the former the leading candidate".

Here we propose an alternative hypothesis for the latitudinal gradient. But first, we make two general comments on the original conclusions: (1) models predicting the isotope composition of dry matter in $\mathrm{C} 3$ plants show that the $\delta^{13} \mathrm{C}$ is a function of the ratio of intercellular to ambient $\mathrm{CO}_{2}$ concentrations, $\mathrm{Ci} / \mathrm{Ca}$ (ref. 2). The effect of environmental stresses and physiological influences will be via differential effects on assimilation rate and leaf conductance that result in variations in this ratio. There are many empirical studies on the influences on $\delta^{13} \mathrm{C}$ in plant material (including the latitude, altitude and metabolism effects suggested by Stuiver and Braziunas) which should be re-examined from this perspective.

(2) Significant variations have been observed in unstressed plants both among species and among cultivars within species possessing the $\mathrm{C} 3$ photosynthetic pathway. The reported latitudinal variation in $\delta^{13} \mathrm{C}$ results primarily from the mean differences between species, with each species exhibiting a scatter of about $1 \%$ around the mean. The one exception to this is provided by a single high-latitude Douglas fir, which is around 1-2\% depleted in ${ }^{13} \mathrm{C}$ compared with the mean of mid-latitude Douglas firs. Similarly, for other tree-ring $\delta^{13} \mathrm{C}$ data summarized by Stuiver and Braziunas, the range for any one species seems to be about $2 \%$ (with no information on selection criteria). Thus the available information, although exhibiting a $\delta^{13} \mathrm{C}$ dependence on latitude, does not permit a clear distinction between possible genetic and environmental causes.

Nevertheless, because of the potential importance of tree-ring isotope measurements to studies of the palaeo-environment and, for example, to contemporary forest ecology, we propose one environmental mechanism which provides a latitudinal variation in $\delta^{13} \mathrm{C}$ of the sign and magnitude observed.

In terms of the bulk of carbon assimilated by the coniferous trees studied by one of us and colleagues ${ }^{3}$, the dominant influence on $\delta^{13} \mathrm{C}$ was light level. To sustain an argument that this light-dominated mechanism applies to the latitudinalgradient data of Stuiver and Braziunas, it is necessary to demonstrate that light is a growth-limiting factor for the species involved, over the relevant latitude range $\left(35^{\circ}\right.$ to $\left.65^{\circ} \mathrm{N}\right)$

Using data from the world actinometric network, Budyko ${ }^{4}$ computed values for the photosynthetically active radiation for the 'vegetation season' for different regions of the Soviet Union. Using these data, and including the influence of temperature, turbulent exchange and respiration, he estimated potential vegetation yields (amount of assimilated $\mathrm{CO}_{2}$ per unit area) as a function of latitude (moisture non-limiting). The strong dependence in potential yield, going from $70^{\circ} \mathrm{N}$ to $40^{\circ} \mathrm{N}$, is attributable largely to radiation flux. In the sense that the variation in $\delta^{13} \mathrm{C}$ in the leaf model represents a kinetic fractionation (depending on the rate rather than the amount of assimilation), the results of Budyko are more appropriate here than actual measurements of yield, in which many time-related and tissue-capacity factors can limit growth.

Budyko's 'light curves' exhibit appreciable slope (assimilation dependence) below about $0.3 \mathrm{cal} \mathrm{cm}^{-2} \mathrm{~min}^{-1}$, which is equivalent to a photosynthetic photonflux density of around $400 \mu \mathrm{mol} \mathrm{m} \mathrm{m}^{-2} \mathrm{~s}^{-1}$. Photosynthetically active radiation over the vegetation season ranges from $70 \mathrm{kcal}$ $\mathrm{cm}^{-2}$ at $35^{\circ} \mathrm{N}$ to $20 \mathrm{kcal} \mathrm{cm}^{-2}$ at $65^{\circ} \mathrm{N}$. These represent similar changes to those which produced observed $\delta^{13} \mathrm{C}$ changes of around $4 \%$ in individual trees ${ }^{3}$ (in agreement with model prediction if translocation effects are assumed). These, in turn, are of similar sign and magnitude to the reported tree ring $\delta^{13} \mathrm{C}$ difference of 4-5\%o over this latitude range

From these observations, it seems that radiation level could be major factor in determining the average tree ring $\delta^{13} \mathrm{C}$ in the mid-to-high latitude bands, possible outweighing genetic differences for some species. The converse argument is that the average $\delta^{\prime} \mathrm{C}$ of tree rings indicates potential yield.

CSIRO Division of Atmospheric Research, Aspendale,

Victoria 3195, Australia

K.T. HuBICK

Department of Environmental Biology,

Australian National University,

Canberra, ACT 260)1, Australia
Stuiver and Braziunas Repi.y-As we noted', the ${ }^{13} \mathrm{C} /{ }^{13} \mathrm{C}$ offset between tree cellulose and atmospheric $\mathrm{CO}$, can depend on many environmental parameters, such as precipitation, temperature, physiology, light intensity, nutrients and relative humidity. As a possible interpretation for the demonstrated latitude dependency of $\delta^{13} \mathrm{C}$ of trees, we focused on relative humidity and temperature. Francey and Hubik, although concerned about possible genetic influences on the latitude relationship, suggest that the controlling factor is light intensity. Latitudedependent light intensity, as well as nutrient availability, indeed should contribute to the observed relationship. But we are not convinced that light intensity overrides all other components of this complex system.

Support for the dominance of light intensity of $\delta^{\prime \prime} \mathrm{C}$ is taken from the work of Francey et al. ${ }^{3}$ on physiological influences on carbon-isotope discrimination in Huon pine. A $1 \% \delta^{13} \mathrm{C}$ difference of $6.6 \%$ is calculated between a sunny and shaded branch of Huton pine, whereas the observed difference is $2.1 \%$. The authors assume translocation to be the attenuating factor, but do not offer independent experimental evidence (such as the use of ${ }^{14} \mathrm{C}$ tracer) that provides the magnitude of inter-branch translocation for Huon pines. For red pine, each branch appears to be in a large measure self-supportings.

Extrapolating the Huon pine study to other species is problematical. Huon pine has a stomatal insensitivity to light, whereas most species exhibit substantial response to light ${ }^{2}$. There is no evidence of a humidity response of Huon pine needles, a factor possibly related to the suggestion of unusually low stomatal conductances observed in field Huon pine compared with those of most species ${ }^{2}$. Evidently, the anomalous genetic make up of Huon pine could result in a $\delta^{13} \mathrm{C}$ response substantially different from that of most other species.

Light intensity is an important factor influencing $\delta^{13} \mathrm{C}$ in trees ${ }^{n}$. However, the proposed quantitative framework for interpretation of a latitude relationship dominated solely by light intensity may be too limited.

Minze StuIVer Thomas F Braziunas

Department of Geological Sciences and Quaternary Research Center.

University of Washington,

Seattle, Washington 98195, USA

1. Stuiver, M \& Braziunas. T.F. Nature 328, 58-60(1987)

2. Farghar. (i.D.OOLeary. M.H.\& Berry. J.A. Aust J. Plan Physiol. 9. 121-137(1982)

Francey, R.J., Gifford. R.M. Sharkey, T.D. \& Weir, B Oecologia i Berlin) 66. 211-218(1985)

4 Budvko. M.I. Agroclimatological Methods - Methodes Agroctimatologiques (UNESCO, 1968).

Rangnckar, P.V. Forward, D.V. \& Nolan, N.J. Can J Bot. 47, $17(01-1711$ (1969).

h. Ehleringer, J.R. Field. C.B., Zhi-fang Lin \& Chun-yeo Kuo Decotogia 70, 520-526(1986) 